\title{
Impact of obesity on glucose and lipid profiles in adolescents at different age groups in relation to adulthood Gilles Plourde
}

Address: Faculty of Health Sciences, School of Human Kinetics, University of Ottawa, Ontario, Canada

E-mail: dr_plourde@hotmail.com

Published: 14 October 2002

Received: 14 March 2002

BMC Family Practice 2002, 3:18

Accepted: 14 October 2002

This article is available from: http://www.biomedcentral.com/147I-2296/3/18

(c) 2002 Plourde; licensee BioMed Central Ltd. This article is published in Open Access: verbatim copying and redistribution of this article are permitted in all media for any purpose, provided this notice is preserved along with the article's original URL.

\begin{abstract}
Background: As obesity is rapidly becoming a major medical and public health problem, the aim of our study was to determine: I) if obesity in Caucasian adolescents at 5 different Tanner stages are associated with obesity in adulthood and its obesity-associated abnormal glucose and lipid profiles, 2) the type of fat distribution is associated with glucose and lipid profile abnormalities, and 3 ) the risk level and the age of appearance of these abnormalities.

Methods: For the first study, data analyses were from a case-control study of adolescents classified according to their BMI; a BMI $\geq 85^{\text {th }}$ percentile for age and sex as overweight, and those with a BMI $\geq 95^{\text {th }}$ percentile as obese. Subjects with a BMI $<85^{\text {th }}$ percentile were classified as controls. WC:AC ratio of waist circumference to arm circumference was used as an indicator of a central pattern of adiposity. Two other indices of central adiposity were calculated from skinfolds: Centralperipheral (CPR) as subscapular skinfold + suprailliac skinfold)/ (triceps skinfold + thigh skinfold) and ratio of subscapular to triceps skinfold (STR). The sum of the four skinfolds (SUM) was calculated from triceps, subscapular, suprailliac and thigh skinfolds. SUM provides a single measure of subcutaneous adiposity. Representative adult subjects were used for comparison. Glucose and lipid profiles were also determined in these subjects. Abnormal glucose and lipid profiles were determined as being those with fasting glucose $\geq 6.1 \mathrm{mmol} / \mathrm{l}$ and lipid values $\geq 85^{\text {th }}$ percentile adjusted for age and sex, respectively. Prevalence and odds ratio analysis were used to determine the impact of obesity on glucose and lipid profiles at each Tanner stages for both sexes. Correlation coefficient analyses were used to determine the association between glucose and lipid profiles and anthropometric measurements for both sexes. The second study evaluated in a retrospectiveprospective longitudinal way if: I) obesity in adolescence is associated with obesity in adulthood and 2) the nature of obesity-associated risk factors. Incidence and odds ratio analysis were used to determine the impact of obesity on glucose and lipid profiles at 7 different age groups from 9 to 38 years old in both sexes between 1974 to 2000.
\end{abstract}

Results: Overall, glucose and lipid profiles were significantly $(P<0.01)$ associated with all anthropometric measurements either in male and female adolescents. WC:AC, CPR, STR and SUM are stronger predictors of both glucose and lipid profiles than BMI. Obese and overweight adolescents of Tanner stages III and higher are at increased risk of having an impaired glucose and lipid profiles than normal subjects with odds ratios of 5.9 and higher. Obesity in adolescents of $13-$ 15 years old group is significantly $(P<0.01)$ associated with obesity in adulthood (with odds ratios of at least 12 for both men and women) and abnormal glucose (odds ratio of $\geq 8.6$ ) and lipid profiles (odds ratio of $\geq 11.4$ ). 


\begin{abstract}
Conclusions: This study confirmed that adolescents aged between I 3 and I 5 years old of both sexes with a BMI $\geq 85^{\text {th }}$ percentile are at increased risk of becoming overweight or obese adults and presenting abnormal glucose and lipid profiles as adults. This emphasizes the importance of early detection and intervention directed at treatment of obesity to avert the long-term consequences of obesity on the development of cardiovascular diseases.
\end{abstract}

\section{Background}

Obesity is rapidly becoming one of the most important medical and public health problems of our time. Obesity is associated with a high rate of morbidity and early mortality if left untreated [1-4]. Studies indicate that the presence of obesity increases the risk for developing cardiovascular diseases and diabetes [5-8]. Its role as a health hazard in adults has been well recognized for some time [1-13] but little attention has been paid to childhood and adolescent obesity [14-17].

The prevalence of obesity among US children is approximately of $22-30 \%$ and has increased at an accelerating rate in the past several years [18-20]; the prevalence of obesity is $>30 \%$ in some pediatric populations $[20,21]$. Obesity in childhood is associated with obesity in adulthood [22-25], and is a predictor of all causes of obesityassociated mortality during adulthood, particularly mortality from cardiovascular diseases, which are independent of adult weight [24,25]. Epidemiologic evidence supports the theory that the relation between obesity and disease risk begins early in life. For instance, adolescents who died in accidents had fatty streaks in the coronary arteries and aorta that were found at, autopsy, and were associated with blood lipid profile, blood pressure, and obesity status obtained at one or more points antemortem $[26,27]$. Moreover, a recent longitudinal study indicated that the occurrence of overweight, hypertension, and dyslipidemia in young adults (aged 19-32 y) was associated with these same risk factors in childhood. Data from the Children's Hospital Medical Center in Cincinnati have shown that the incidence of type 2 diabetes among adolescents increased 10-fold from 1982 to 1994, and virtually all diagnosed cases of type 2 diabetes occurred in obese individuals [28]. These observations are likely to reflect national trends and certainly deserve both confirmation, and a sharper focus.

To test the hypothesis that being an overweight or obese adolescent is associated with early appearance of glucose and lipid profile abnormalities, we performed a case-control study quantifying the odds ratio of overweight and obesity on these abnormalities through different Tanner's stages. The association between glucose and lipid profiles and the distribution of adipose tissue was also tested in this study. The objective of the second study was to determine. from a retrospective-prospective longitudinal study of overweight and obese male and females having abnormal glucose and/or lipid profiles at which age obesity in adolescence can be predictive of adult obesity and its obesity-associated cardiovascular risk factors.

\section{Methods \\ Study I}

The first investigation was designed as a case-control study and was performed in hospitals associated with Montreal and McGill Universities. Many of the subjects were also directly recruited from nursery schools. This study was conducted to determine the relationship between various indicators of adiposity and risk factors for cardiovascular diseases in Caucasian normal, overweight, and obese male and female adolescents. The prevalence and odds ratio of being overweight or obese on glucose and lipid profiles was also determined. Each Tanner stage is associated with important changes in genital development and sexual hormone profiles, which could have an impact on adipose tissue distribution and glucose and lipid profiles. Informed written consent was obtained from the parents and/or of all participating subjects. The participants were recruited from local and national advertising. To be included in the study, adolescents and adults had to meet the following criteria: 1) be of Caucasian ethnicity; 2) be free from diagnosed endocrine conditions that could lead to obesity, and 3) not taking any medication affecting body weight. They were selected for the study on the basis of their body mass index. Standing height was measured with a wall-mounted tape, and weight was measured with the same standard balance scale.

Adolescents were classified according to $\mathrm{BMI} ; \geq 85^{\text {th }}$ percentile as overweight, and $\geq 95^{\text {th }}$ percentile for age and sex as obese [29-32]. Recent workshops concluded that the BMI has been validated by studies on total body fat [32]. The standards used to identify overweight and obesity in children and adolescents should agree with the standards used to identify grade 1 and grade 2 overweight (BMI of 25 and 30, respectively) in adults [33]. Adolescents with a $\mathrm{BMI}<85^{\text {th }}$ percentile were classified as controls (Group $1)$, Group 2 were overweight $\left(\mathrm{BMI}>85^{\text {th }}\right.$ percentile and $<$ $95^{\text {th }}$ percentile) and group 3 were obese (BMI $\geq 95^{\text {th }}$ percentile). Adults with a BMI $<25$ were classified as controls, between 25 and 30 as overweight and $\geq 30$ as obese. Sexes were grouped separately. 
Table I: Anthropometric measurements with categories of BMI and Tanner stages. A group of adults was also used for comparison purpose. Adults with a BMI $<25$ were classified as controls, between 25 and 30 as overweight and $\geq 30$ as obese. A BMI of 25 and 30 correspond to $85^{\text {th }}$ and $95^{\text {th }}$ percentile respectively.

\begin{tabular}{|c|c|c|c|c|c|c|}
\hline Tanner's Stage & Age (years) & BMI(\%) & WC:AC (ratio) & CPR (ratio) & STR (Index) & SUM \\
\hline \multicolumn{7}{|l|}{ Male } \\
\hline \multicolumn{7}{|l|}{ Tanner I } \\
\hline Normal $(n=38)$ & $10.7 \pm 0.4$ & $76.7 \pm 1.8$ & $2.3 \pm 0.05$ & $1.3 \pm 0.04$ & $0.7 \pm 0.02$ & $51 \pm 6$ \\
\hline Overweight $(n=36)$ & $10.8 \pm 0.5$ & $87.2 \pm 1.0$ & $3.0 \pm 0.07$ & $1.7 \pm 0.04$ & $0.9 \pm 0.02$ & $70 \pm 9$ \\
\hline Obese $(n=34)$ & $10.6 \pm 0.6$ & $96.7 \pm 1.1$ & $3.4 \pm 0.07$ & $2.2 \pm 0.05$ & $1.3 \pm 0.04$ & $86 \pm 11$ \\
\hline \multicolumn{7}{|l|}{ Tanner II } \\
\hline Normal $(n=35)$ & $11.9 \pm 0.6$ & $76.4 \pm 2.0$ & $2.4 \pm 0.03$ & $1.2 \pm 0.03$ & $0.6 \pm 0.02$ & $47 \pm 8$ \\
\hline Overweight $(n=32)$ & $11.8 \pm 0.6$ & $88.3 \pm 1.4$ & $3.1 \pm 0.06$ & $1.7 \pm 0.05$ & $0.9 \pm 0.02$ & $76 \pm 8$ \\
\hline Obese $(n=35)$ & $11.8 \pm 0.5$ & $97.1 \pm 1.0$ & $3.6 \pm 0.05$ & $2.3 \pm 0.03$ & $1.4 \pm 0.03$ & $90 \pm 7$ \\
\hline \multicolumn{7}{|l|}{ Tanner III } \\
\hline Normal $(n=39)$ & $13.3 \pm 0.7$ & $77.4 \pm 2.3$ & $2.4 \pm 0.02$ & $1.4 \pm 0.04$ & $0.8 \pm 0.03$ & $49 \pm 8$ \\
\hline Overweight $(n=36)$ & $13.2 \pm 0.6$ & $88.9 \pm 1.1$ & $3.3 \pm 0.07$ & $2.0 \pm 0.04$ & $1.3 \pm 0.02$ & $85 \pm 10$ \\
\hline Obese $(n=36)$ & $13.3 \pm 0.5$ & $97.4 \pm 0.9$ & $4.2 \pm 0.09$ & $2.5 \pm 0.05$ & $1.8 \pm 0.03$ & $110 \pm 9$ \\
\hline \multicolumn{7}{|l|}{ Tanner IV } \\
\hline Normal $(n=33)$ & $13.9 \pm 0.5$ & $78.1 \pm 3.2$ & $2.5 \pm 0.05$ & $1.5 \pm 0.03$ & $0.8 \pm 0.02$ & $53 \pm 8$ \\
\hline Overweight $(n=3 I)$ & $14.0 \pm 0.5$ & $90.0 \pm 1.1$ & $3.4 \pm 0.08$ & $2.1 \pm 0.03$ & $\mathrm{I} .4 \pm 0.03$ & $88 \pm 12$ \\
\hline Obese $(n=33)$ & $13.8 \pm 0.6$ & $96.8 \pm 0.4$ & $4.1 \pm 0.09$ & $2.6 \pm 0.05$ & $1.9 \pm 0.02$ & $108 \pm 11$ \\
\hline \multicolumn{7}{|l|}{ Tanner V } \\
\hline Normal $(n=38)$ & $14.6 \pm 0.3$ & $79.5 \pm 2.4$ & $2.5 \pm 0.04$ & $1.4 \pm 0.04$ & $0.7 \pm 0.03$ & $54 \pm 7$ \\
\hline Overweight $(n=35)$ & $14.6 \pm 0.5$ & $87.4 \pm 0.8$ & $3.4 \pm 0.05$ & $2.1 \pm 0.05$ & $1.3 \pm 0.02$ & $86 \pm 12$ \\
\hline Obese $(n=36)$ & $14.7 \pm 0.4$ & $96.6 \pm 0.4$ & $3.9 \pm 0.08$ & $2.6 \pm 0.06$ & $2.0 \pm 0.02$ & $115 \pm 14$ \\
\hline \multicolumn{7}{|l|}{ ADULTS } \\
\hline Normal $(n=44)$ & $31.2 \pm 0.3$ & $22.2 \pm 0.5$ & $2.4 \pm 0.03$ & $1.4 \pm 0.04$ & $0.7 \pm 0.02$ & $54 \pm 8$ \\
\hline Overweight $(n=43)$ & $30.6 \pm 0.6$ & $28.4 \pm 0.8$ & $4.1 \pm 0.05$ & $2.4 \pm 0.06$ & $1.5 \pm 0.02$ & $106 \pm 12$ \\
\hline Obese $(n=45)$ & $31.5 \pm 0.4$ & $33.6 \pm 0.4$ & $4.9 \pm 0.07$ & $2.9 \pm 0.05$ & $2.4 \pm 0.02$ & $145 \pm 14$ \\
\hline \multicolumn{7}{|l|}{ Female } \\
\hline \multicolumn{7}{|l|}{ Tanner I } \\
\hline Normal $(n=35)$ & $10.3 \pm 0.5$ & $76.3 \pm 2.8$ & $2.3 \pm 0.05$ & $1.2 \pm 0.04$ & $0.8 \pm 0.01$ & $48 \pm 5$ \\
\hline Overweight $(n=30)$ & $10.3 \pm 0.6$ & $88.2 \pm 1.0$ & $2.9 \pm 0.07$ & $1.6 \pm 0.04$ & $0.9 \pm 0.02$ & $72 \pm 8$ \\
\hline Obese $(n=33)$ & $10.2 \pm 0.5$ & $96.0 \pm 0.3$ & $3.4 \pm 0.09$ & $1.9 \pm 0.03$ & $1.0 \pm 0.03$ & $88 \pm 7$ \\
\hline \multicolumn{7}{|l|}{ Tanner II } \\
\hline Normal $(n=31)$ & $11.4 \pm 0.6$ & $77.3 \pm 2.0$ & $2.4 \pm 0.04$ & $1.3 \pm 0.04$ & $0.8 \pm 0.02$ & $54 \pm 9$ \\
\hline Overweight $(n=32)$ & $11.3 \pm 0.5$ & $89.1 \pm 1.9$ & $3.2 \pm 0.06$ & $1.9 \pm 0.05$ & $1.2 \pm 0.02$ & $78 \pm 8$ \\
\hline Obese $(n=29)$ & $1 \mathrm{I} .4 \pm 0.7$ & $97.4 \pm 0.6$ & $3.7 \pm 0.08$ & $2.2 \pm 0.04$ & $1.5 \pm 0.03$ & $90 \pm 9$ \\
\hline \multicolumn{7}{|l|}{ Tanner III } \\
\hline Normal $(n=37)$ & $12.9 \pm 1.0$ & $77.6 \pm 3.0$ & $2.4 \pm 0.04$ & $1.3 \pm 0.03$ & $0.8 \pm 0.03$ & $55 \pm 9$ \\
\hline Overweight $(n=33)$ & $12.8 \pm 0.9$ & $91.6 \pm 2.0$ & $3.5 \pm 0.07$ & $2.2 \pm 0.05$ & $1.1 \pm 0.04$ & $82 \pm 7$ \\
\hline Obese $(n=32)$ & $12.9 \pm 0.7$ & $97.5 \pm 0.5$ & $4.1 \pm 0.07$ & $2.5 \pm 0.04$ & $1.5 \pm 0.03$ & $105 \pm 10$ \\
\hline \multicolumn{7}{|l|}{ Tanner IV } \\
\hline Normal $(n=32)$ & $13.6 \pm 0.7$ & $79.1 \pm 1.8$ & $2.3 \pm 0.06$ & $1.4 \pm 0.05$ & $0.9 \pm 0.02$ & $49 \pm 6$ \\
\hline Overweight $(n=29)$ & $13.7 \pm 0.8$ & $90.4 \pm 0.7$ & $3.6 \pm 0.07$ & $2.3 \pm 0.04$ & $1.2 \pm 0.04$ & $90 \pm 11$ \\
\hline Obese $(n=28)$ & $13.8 \pm 0.7$ & $96.8 \pm 0.9$ & $4.0 \pm 0.06$ & $2.5 \pm 0.05$ & $1.5 \pm 0.03$ & $108 \pm 9$ \\
\hline \multicolumn{7}{|l|}{ Tanner V } \\
\hline Normal $(n=33)$ & $14.7 \pm 0.7$ & $79.3 \pm 2.5$ & $2.4 \pm 0.07$ & $1.3 \pm 0.03$ & $1.0 \pm 0.03$ & $49 \pm 6$ \\
\hline Overweight $(n=34)$ & $14.6 \pm 0.8$ & $89.9 \pm 2.0$ & $3.6 \pm 0.06$ & $2.2 \pm 0.04$ & $1.3 \pm 0.03$ & $92 \pm 9$ \\
\hline Obese $(n=34)$ & $14.7 \pm 0.7$ & $97.0 \pm 0.4$ & $3.9 \pm 0.06$ & $2.5 \pm 0.04$ & $1.6 \pm 0.03$ & $107 \pm 8$ \\
\hline \multicolumn{7}{|l|}{ ADULTS } \\
\hline Normal $(n=40)$ & $33.4 \pm 0.3$ & $22.2 \pm 0.4$ & $2.4 \pm 0.02$ & $1.3 \pm 0.03$ & $0.7 \pm 0.01$ & $54 \pm 5$ \\
\hline Overweight $(n=42)$ & $31.2 \pm 0.5$ & $27.8 \pm 0.6$ & $4.3 \pm 0.05$ & $2.7 \pm 0.05$ & $1.4 \pm 0.02$ & $116 \pm 16$ \\
\hline Obese $(n=40)$ & $33.5 \pm 0.5$ & $32.6 \pm 0.5$ & $4.7 \pm 0.07$ & $3.0 \pm 0.06$ & $2.6 \pm 0.03$ & $150 \pm 17$ \\
\hline
\end{tabular}

The results are expressed as means $\pm S D$. $P<0.0$ I Normal vs overweight and $P<0.001$ Normal vs Obese for either male and female. There is no differences between males and females for the variables measured WC:AC: waist to arm circumference. CPR: subscapular skinfold + suprailliac skinfold) / (triceps skinfold+ thigh skinfold), STR: ratio of subscapular to triceps skinfold, SUM:triceps, subscapular, suprailliac and thigh skinfolds in the total sample. 
Table 2: Prevalence of impaired fasting glucose and lipid profile by categories of BMI in adolescents at different Tanner's stages and sex. A group of adults was used for comparison purpose.

\begin{tabular}{|c|c|c|c|c|c|}
\hline \multirow[b]{2}{*}{ Tanner's Stages } & \multirow[b]{2}{*}{$\mathrm{N}$} & \multicolumn{2}{|c|}{ Impaired glucose profile } & \multicolumn{2}{|c|}{ Impaired lipid profile } \\
\hline & & No Cases & Prevalence (\%) & No Cases & Prevalence (\%) \\
\hline \multicolumn{6}{|l|}{ Male } \\
\hline \multicolumn{6}{|l|}{ Tanner I } \\
\hline Normal & 38 & 0 & 0 & 0 & 0 \\
\hline Overweight & 36 & 4 & 11.1 & 0 & 0 \\
\hline Obese & 34 & 15 & 44.1 & 4 & 11.7 \\
\hline \multicolumn{6}{|l|}{ Tanner II } \\
\hline Normal & 35 & 0 & 0 & 0 & 0 \\
\hline Overweight & 32 & 5 & 15.6 & 0 & 0 \\
\hline Obese & 35 & 13 & 37.1 & 4 & 11.4 \\
\hline \multicolumn{6}{|l|}{ Tanner III } \\
\hline Normal & 39 & 4 & 10.3 & 3 & 7.7 \\
\hline Overweight & 36 & 13 & 36.1 & 13 & 36.1 \\
\hline Obese & 36 & 28 & 77.7 & 18 & 50.0 \\
\hline \multicolumn{6}{|l|}{ Tanner IV } \\
\hline Normal & 33 & 3 & 9.1 & 5 & 15.2 \\
\hline Overweight & 31 & 14 & 45.1 & 14 & 45.1 \\
\hline Obese & 33 & 31 & 94.0 & 32 & 88.8 \\
\hline \multicolumn{6}{|l|}{ Tanner V } \\
\hline Normal & 38 & 5 & 13.2 & 6 & 15.8 \\
\hline Overweight & 35 & 13 & 37.1 & 14 & 40.0 \\
\hline Obese & 36 & 36 & 100 & 32 & 88.8 \\
\hline \multicolumn{6}{|l|}{ ADULTS } \\
\hline Normal & 44 & 6 & 13.6 & 6 & 13.6 \\
\hline Overweight & 43 & 18 & 41.8 & 17 & 39.5 \\
\hline Obese & 45 & 42 & 100 & 42 & 93.3 \\
\hline \multicolumn{6}{|l|}{ Female } \\
\hline \multicolumn{6}{|l|}{ Tanner I } \\
\hline Normal & 35 & 0 & 0 & 0 & 0 \\
\hline Overweight & 30 & 3 & 10 & 0 & 0 \\
\hline Obese & 33 & 12 & 36.4 & 4 & 12.1 \\
\hline \multicolumn{6}{|l|}{ Tanner II } \\
\hline Normal & 31 & 0 & 0 & 0 & 0 \\
\hline Overweight & 32 & 4 & 12.5 & 0 & 0 \\
\hline Obese & 29 & 13 & 44.8 & 4 & 13.8 \\
\hline \multicolumn{6}{|l|}{ Tanner III } \\
\hline Normal & 37 & 5 & 13.5 & 5 & 13.5 \\
\hline Overweight & 33 & 12 & 36.4 & 13 & 39.4 \\
\hline Obese & 32 & 26 & 81.3 & 18 & 56.3 \\
\hline \multicolumn{6}{|l|}{ Tanner IV } \\
\hline Normal & 32 & 4 & 12.5 & 4 & 12.5 \\
\hline Overweight & 29 & 17 & 58.6 & 14 & 48.2 \\
\hline Obese & 28 & 24 & 85.7 & 25 & 86.2 \\
\hline \multicolumn{6}{|l|}{ Tanner V } \\
\hline Normal & 33 & 4 & 12.1 & 5 & 15.2 \\
\hline Overweight & 34 & 13 & 38.2 & 14 & 41.1 \\
\hline Obese & 34 & 29 & 85.3 & 31 & 91.1 \\
\hline \multicolumn{6}{|l|}{ ADULTS } \\
\hline Normal & 40 & 6 & 15.0 & 6 & 15.0 \\
\hline Overweight & 42 & 17 & 40.5 & 17 & 40.5 \\
\hline Obese & 40 & 40 & 100 & 37 & 92.5 \\
\hline
\end{tabular}


WC:AC was calculated from the ratio of waist circumference to arm circumference and used as a measured of fat distribution analogous to waist to hip ratio, on the assumption that a higher ratio of waist to arm circumference is an indicator of a more central pattern of adiposity. We used this measure in preference to waist to hip ratio, because a study which determined peripheral and abdominal adipose tissue content in children using magnetic resonance imaging found that $\mathrm{WC}$ :AC correlated positively with intra-abdominal adipose tissue $(\mathrm{r} \pm 0.63, \mathrm{P}=$ $0.001)$ while waist to hip ratio did not $(r=0.11)$ [34]. Two other indices of central adiposity were calculated from skinfolds: Central-peripheral (CPR) as subscapular skinfold + suprailliac skinfold) / (triceps skinfold+ thigh skinfold) and ratio of subscapular to triceps skinfold (STR). STR is an index of relative distribution of central subcutaneous adiposity. The sum of the four skinfolds (SUM) was calculated from triceps, subscapular, suprailliac and thigh skinfolds in the total sample. The SUM provides a single measure of subcutaneous adiposity. Anthropometric measurements were done by the same experienced evaluator to reduce variability which was measured at less than $0.5 \%$.

Table 3: Sensitivity, specificity, and odds ratios for impaired glucose profile (IGP) vs normal glucose profile (NGP) levels for both sex at Tanner's stages 3 to 5 with a selected cutoff point for BMI values at the $8^{\text {th }}$ percentile.

\begin{tabular}{|c|c|c|c|c|c|}
\hline \multirow[t]{2}{*}{ Tanner's stages } & \multicolumn{2}{|c|}{ Cutoff point for BMI values } & \multirow[t]{2}{*}{ Sensitivity } & \multirow[t]{2}{*}{ Specificity } & \multirow[t]{2}{*}{ Odds ratio } \\
\hline & $>85^{\text {th }}$ & $<85^{\text {th }}$ & & & \\
\hline \multicolumn{6}{|l|}{$\begin{array}{l}\text { Tanner III } \\
\text { Males }\end{array}$} \\
\hline $\operatorname{IGP}(n=47)$ & 43 & 4 & & $91 \%$ & \\
\hline$N G P(n=54)$ & 19 & 35 & $64.8 \%$ & & \\
\hline Total $(n=101)$ & 62 & 39 & & & 19.6 \\
\hline \multicolumn{6}{|l|}{ Females } \\
\hline $\operatorname{IGP}(n=43)$ & 38 & 5 & & $88.4 \%$ & \\
\hline $\operatorname{NGP}(n=44)$ & 12 & 32 & $72.7 \%$ & & \\
\hline Total $(\mathrm{n}=87)$ & 50 & 37 & & & 20.3 \\
\hline \multicolumn{6}{|l|}{ Tanner IV } \\
\hline \multicolumn{6}{|l|}{ Males } \\
\hline $\operatorname{IGP}(n=48)$ & 45 & 3 & & $93.5 \%$ & \\
\hline $\operatorname{NGP}(n=48)$ & 18 & 30 & $71.4 \%$ & & \\
\hline Total $(n=96)$ & 63 & 33 & & & 23.7 \\
\hline \multicolumn{6}{|l|}{ Females } \\
\hline $\operatorname{IGP}(n=45)$ & 41 & 4 & & $93.2 \%$ & \\
\hline $\operatorname{NGP}(n=45)$ & 17 & 29 & $64.4 \%$ & & \\
\hline Total $(n=90)$ & 58 & 32 & & & 17.5 \\
\hline \multicolumn{6}{|l|}{ Tanner V } \\
\hline \multicolumn{6}{|l|}{ Males } \\
\hline IGP(n = 54) & 49 & 5 & & $90.7 \%$ & \\
\hline $\operatorname{NGP}(n=55)$ & 22 & 33 & $60 \%$ & & \\
\hline Total $(n=109)$ & 71 & 38 & & & 14.7 \\
\hline \multicolumn{6}{|l|}{ Females } \\
\hline $\operatorname{IGP}(n=46)$ & 42 & 4 & & $87.9 \%$ & \\
\hline $\operatorname{NGP}(n=55)$ & 26 & 29 & $61.8 \%$ & & \\
\hline Total $(n=101)$ & 68 & 33 & & & 11.7 \\
\hline \multicolumn{6}{|l|}{ Adults } \\
\hline \multicolumn{6}{|l|}{ Males } \\
\hline $\operatorname{IGP}(n=69)$ & 63 & 6 & & $86.4 \%$ & \\
\hline $\operatorname{NGP}(n=63)$ & 25 & 38 & $64.3 \%$ & & \\
\hline Total $(n=132)$ & 98 & 44 & & & 16.0 \\
\hline \multicolumn{6}{|l|}{ Females } \\
\hline $\operatorname{IGP}(n=63)$ & 57 & 6 & & $85 \%$ & \\
\hline $\operatorname{NGP}(n=59)$ & 25 & 34 & $69.5 \%$ & & \\
\hline Total $(n=122)$ & 82 & 40 & & & 12.9 \\
\hline
\end{tabular}

An odds ratio of 19.6 means that the risk of IFG is 19.6 times higher in Tanner's stage 3 adolescents who are having a BMI > $85^{\text {th }}$ than in those with a BMI < than $85^{\text {th }}$ percentile. 
Genital development was evaluated with the criteria of Tanner [35], and was performed with a questionnaire and physical exam by an experienced physician, in which stage 1 is prepubertal, stage 2 is initial development of the genitalia, stages 3 and 4 are intermediate, and stage 5 is mature. Stage of sexual maturation in the girls was determined on the basis of a combination of menarcheal status and breast and pubic hair development [36]. The stages of sexual maturation were performed with a questionnaire and physical exam done by an experienced physician as follow: premenarcheal with no secondary sexual development (stage 1). Premenarcheal with some secondary sexual development (stage 2); premenarcheal at the time of study but attained menarche within 6 months (stage 3); postmenarcheal with secondary sexual development not yet mature (stage 4); and postmenarcheal with secondary sexual development (stage 5).

The subjects were instructed to arrive to the clinic at 8:00 AM after 12-hour overnight fast. BMI was measured and a venous blood sample was taken followed by a breakfast. Fasting blood samples were stored at 4C. Serum glucose and insulin levels and lipid profile were determined. They completed a questionnaire on risk factors for atherosclerosis including family history of coronopathy, smoking, high blood pressure, personal history of coronopathy or myocardial infarct, history of cerebrovascular disease or occlusive peripheral disease. Most overweight and obese subjects had at least two risk factors for atherosclerosis.

The diagnostic criteria for glucose profile were those approved by the American Diabetes Association [37]. Diabetes is defined as a fasting serum glucose equal or higher than $7 \mathrm{mmol} / \mathrm{L}(126 \mathrm{mg} / \mathrm{dl})$ and impaired fasting glucose with values between 6.0 and $7.0 \mathrm{mmol} / \mathrm{L}$. Subjects with high fasting glucose levels were referred to their own physicians for further clinical evaluation.

Lipid profile was also performed on the fasting blood sample. The blood lipid variables investigated were triglyceride (TRG), total cholesterol (TC), high-density lipoprotein (HDL) cholesterol concentrations, low-density lipoproteins (LDL) cholesterol concentrations and the ratio of total:HDL cholesterol (T:HDLC) [38]. All biochemical measurements were performed in an accredited hospital laboratory.

\section{Study 2}

The second investigation was designed as a retrospectiveprospective longitudinal study from 1974 to 2000 and was performed from hospitals associated with Montreal and McGill Universities. This study was conducted to determine the age of apparition of abnormal glucose and lipid profiles in a group of overweight and obese young Caucasians adults presenting abnormal glucose and/or li- pid profiles. The study was performed from chart review of participants. 2000 charts were pre-selected by the archivists. To be included in the study, young adults had to meet the following criteria: 1 ) be of Caucasian ethnicity; 2 ) be between the ages of 32-38 y; 3) be free from diagnosed endocrine conditions that could have led to obesity, 4) not having taken any medication affecting body weight, 5) presenting a BMI $\geq 25$ at adult age; 6) presenting abnormal glucose and/or lipid profiles; 7) presenting at least 2 risk factors for cardiovascular diseases as explained earlier, and having been seen by their physicians between 1974 to 2000 . Among the 2000 charts, only 128 males and 112 females were having pertinent data at the different 7 age-groups, permitting longitudinal study of all the subjects used in this study. These charts were reviewed by 2 reviwers. A sample of 20 charts were reviewed by the two reviewers to determine variability between reviewers. The inter-chart reviewer differences was less than $0.2 \%$. Data from the subjects were presented by specific age group, which we think may approximate the criteria of Tanner [35] for genital development. WC:AC ratio was removed from the anthropometric measurements because the concept of waist circumference, waist to hip ratio or waist circumference to arm circumference was unknown or not used to quantify central adiposity.

\section{Statistical procedures}

SAS PROC MIXED version 6.11 (SAS Institute, Cary, North Carolina) was used to analyze longitudinal and correlated data. The analyses were interpreted using $\mathrm{P}<$ 0.01 as the level of significance. An unpaired T-test was used to analyze the difference between male and female for each variables measured at each Tanner stages. Pearson correlations were computed to evaluate the relationship between specific continuous variables. Odds ratios were used to quantify risk in our population.

\section{Results \\ Study I}

Table 1 shows the main anthropometric measurements of our study population. Pubertal status was appropriate for age in all subjects; all girls over $14 \mathrm{y}$ had reached menarche and all boys over $14 \mathrm{y}$ had Tanner Stage grades of 3 or more. The distribution of obese and overweight adolescents in our study did not differ from that expected in an average North American population. As defined in methods WC:AC ratio which is an indicator of central adiposity was significantly higher in both $(\mathrm{P}<0.01)$ overweight and $(\mathrm{P}<0.001)$ obese adolescents in comparison with controls, either in adolescents of different Tanner's stages or adults of both sexes. The CPR value which is representative of central-peripheral obesity was also significantly higher $(\mathrm{P}<0.01)$ in both overweight and $(\mathrm{P}<$ 0.001 ) obese adolescents. The same is true for the STR and 
Table 4: Sensitivity, specificity, and odds ratios for impaired lipid profile (ILP) vs normal lipid profile (NLP) for both sex at Tanner's stages 3 to 5 with a selected cutoff point for BMI values at the $85^{\text {th }}$ percentile.

\begin{tabular}{|c|c|c|c|c|c|}
\hline \multirow[t]{2}{*}{ Tanner's stages } & \multicolumn{2}{|c|}{ Cutoff point for BMI values } & \multirow[t]{2}{*}{ Sensitivity } & \multirow[t]{2}{*}{ Specificity } & \multirow[t]{2}{*}{ Odds ratio } \\
\hline & $>85^{\text {th }}$ & $<85^{\text {th }}$ & & & \\
\hline \multicolumn{6}{|l|}{ Tanner III } \\
\hline \multicolumn{6}{|l|}{ Males } \\
\hline $\operatorname{ILP}(n=34)$ & 31 & 3 & & $91.2 \%$ & \\
\hline $\operatorname{NLP}(n=77)$ & 41 & 36 & $46.7 \%$ & & \\
\hline Total $(n=111)$ & 72 & 39 & & & 9.1 \\
\hline \multicolumn{6}{|l|}{ Females } \\
\hline $\operatorname{ILP}(n=36)$ & 31 & 5 & & $86.1 \%$ & \\
\hline $\operatorname{NLP}(n=66)$ & 34 & 32 & $48.5 \%$ & & \\
\hline Total $(n=102)$ & 65 & 37 & & & 5.9 \\
\hline \multicolumn{6}{|l|}{ Tanner IV } \\
\hline \multicolumn{6}{|l|}{ Males } \\
\hline $\operatorname{ILP}(n=48)$ & 43 & 5 & & $89.6 \%$ & \\
\hline $\operatorname{NLP}(n=59)$ & 31 & 28 & $47.5 \%$ & & \\
\hline Total $(n=107)$ & 64 & 33 & & & 7.8 \\
\hline \multicolumn{6}{|l|}{ Females } \\
\hline $\operatorname{ILP}(n=43)$ & 39 & 4 & & $87.5 \%$ & \\
\hline $\operatorname{NLP}(n=46)$ & 18 & 28 & $83 \%$ & & \\
\hline Total $(\mathrm{n}=89)$ & 47 & 32 & & & 15.2 \\
\hline \multicolumn{6}{|l|}{ Tanner $\mathbf{V}$} \\
\hline \multicolumn{6}{|l|}{ Males } \\
\hline $\operatorname{ILP}(n=54)$ & 48 & 6 & & $88.8 \%$ & \\
\hline $\operatorname{NLP}(n=55)$ & 23 & 32 & $58.2 \%$ & & \\
\hline Total $(n=109)$ & 71 & 38 & & & II.I \\
\hline \multicolumn{6}{|l|}{ Females } \\
\hline $\operatorname{ILP}(n=50)$ & 45 & 5 & & $84.8 \%$ & \\
\hline $\operatorname{NLP}(n=51)$ & 22 & 28 & $66.2 \%$ & & \\
\hline Total $(\mathrm{n}=101)$ & 68 & 33 & & & 11.5 \\
\hline \multicolumn{6}{|l|}{ Adults } \\
\hline \multicolumn{6}{|l|}{ Males } \\
\hline $\operatorname{ILP}(n=65)$ & 59 & 6 & & $86.4 \%$ & \\
\hline $\operatorname{NLP}(n=67)$ & 29 & 38 & $67.0 \%$ & & \\
\hline Total $(n=132)$ & 88 & 44 & & & 12.9 \\
\hline \multicolumn{6}{|l|}{ Females } \\
\hline $\operatorname{ILP}(n=60)$ & 54 & 6 & & $85 \%$ & \\
\hline $\operatorname{NLP}(n=62)$ & 28 & 34 & $65.8 \%$ & & \\
\hline Total $(n=122)$ & 82 & 40 & & & 10.9 \\
\hline
\end{tabular}

Normal lipid profile values were those $<75^{\text {th }}$ percentile for age and sex, moderate risk $>75^{\text {th }}$ percentile and $<90^{\text {th }}$ percentile, and high risk $\geq 90^{\text {th }}$ percentile. For comparison between adolescent and adults percentiles were used. ILP was determined as being $\geq 85^{\text {th }}$ percentile adjusted for age and sex. Normal blood cholesterol level in adults $=\mathrm{TC}<200 \mathrm{mg} / \mathrm{dl}(5.2 \mathrm{mmol} / \mathrm{L})$, moderate risk as 5.2 to $6.2 \mathrm{mmol} / \mathrm{L}$ and high risk if $>6.2 \mathrm{mmol} / \mathrm{l}$ $(240 \mathrm{mg} / \mathrm{dl})$. For LDL cholesterol; normal if $<3.4 \mathrm{mmol} / \mathrm{L}(130 \mathrm{mg} / \mathrm{dl})$, moderate risk as 3.4 to $4.1 \mathrm{mmol} / \mathrm{L}$ and high risk if $>4.1 \mathrm{mmol} / \mathrm{L}(159 \mathrm{mg} / \mathrm{dl})$. $\mathrm{HDL}$ cholesterol was defined at high risk if $<0.9 \mathrm{mmol} / \mathrm{L}(35 \mathrm{mg} / \mathrm{dl})$. TRG levels was normal if $<2.8 \mathrm{mmol} / \mathrm{l}(250 \mathrm{mg} / \mathrm{dl})$, moderate risk as $250-500$ $\mathrm{mg} / \mathrm{dl}$ and high risk if $>5.6 \mathrm{mmol} / \mathrm{L}(500 \mathrm{mg} / \mathrm{dl})$. [38]

SUM values. For all the anthropometric measurements there were no significant differences between sexes.

Table 2 indicates that the prevalence of impaired glucose and lipid profiles were highest among those with a BMI above the $95^{\text {th }}$. The prevalence of impaired fasting glucose is already significant at Tanner stage 1 with percentage prevalence of $11.1 \%$ and $44.1 \%$ for overweight and obese subjects respectively. The prevalence was significantly higher in both $(P<0.01)$ overweight and $(P<0.001)$ obese adolescents in comparison with controls, either in adolescents of different Tanner's stages or adults of both sexes. The prevalence of impaired fasting glucose did not differ significantly between adolescents and adults, either in male or female. Adolescents with BMI exceeding the $85^{\text {th }}$ percentile are at increased risk of being classified as 
Table 5: Correlation between anthropometric variables and fasting glucose levels, insulin levels and lipid profile in male adolescents including all Tanner's stages.

\begin{tabular}{llllll}
\hline Variables & BMI & WC:AC & CPR & STR & SUM \\
\hline Glucose & & & & & \\
Insulin & 0.80 & 0.95 & 0.98 & 0.94 & 0.95 \\
TRG & 0.71 & 0.94 & 0.97 & 0.96 & 0.92 \\
TC & 0.82 & 0.93 & 0.98 & 0.91 & 0.95 \\
HDL & 0.87 & 0.96 & 0.90 & 0.91 & 0.95 \\
LDL & 0.77 & 0.93 & 0.89 & 0.93 & 0.97 \\
T:HDLC & 0.82 & 0.90 & 0.86 & & 0.90 \\
\end{tabular}

All correlation coefficients were statistically significant at least $P<0.01$. See text for abbreviations.

Table 6: Correlation between anthropometric variables and fasting glucose levels, insulin levels and lipid profile in female adolescents including all Tanner's stages.

\begin{tabular}{|c|c|c|c|c|c|}
\hline Variables & BMI & WC:AC & CPR & STR & SUM \\
\hline Glucose & 0.80 & 0.87 & 0.82 & 0.75 & 0.92 \\
\hline Insulin & 0.70 & 0.85 & 0.84 & 0.85 & 0.92 \\
\hline TG & 0.78 & 0.94 & 0.95 & 0.76 & 0.93 \\
\hline $\mathrm{TC}$ & 0.82 & 0.92 & 0.85 & 0.75 & 0.91 \\
\hline HDL & 0.74 & 0.91 & 0.92 & 0.84 & 0.91 \\
\hline LDL & 0.82 & 0.91 & 0.86 & 0.79 & 0.91 \\
\hline T:HDLC & 0.75 & 0.92 & 0.92 & 0.86 & 0.93 \\
\hline
\end{tabular}

All correlation coefficients were statistically significant at least $P<0.01$. See text for abbreviations.

having diabetes or impaired fasting glucose. Also the prevalence of lipid profile abnormalities was highest among those above the $95^{\text {th }}$ percentile for BMI. Adolescents with BMI exceeding the $85^{\text {th }}$ percentile are at increased risk of having abnormal lipid profiles. Again, the difference between the three groups was already present at Tanner stage 1. The presence of an abnormal lipid profile was observed from Tanner stages III and above.

Sensitivity refers to the percentage of obese or overweight participants who were correctly predicted to be at risk for either glucose or lipid profiles abnormalities. Specificity refers to the percentage of participants who were correctly predicted to be in the remaining groups. BMI $>85^{\text {th }}$ percentile were chosen as cutoff point for identifying overweight adolescents and $\mathrm{BMI}<85^{\text {th }}$ percentile were considered as normal subjects. Table 3 shows that the sensitivity and specificity to predict impaired fasting glucose at Tanner stages III and above were at least $60 \%$ and $80 \%$, respectively. With use of this cutoff point, the odds ratio of being at risk for impaired fasting glucose varied from 11.7 to 23.7 for males and females.

Table 4 shows that the sensitivity and specificity to predict an impaired lipid profiles at Tanner stages III and above were from $47.5 \%$ to $83 \%$ (males) and from $84.8 \%$ to $91.2 \%$ (females), respectively. Using a BMI at the $85^{\text {th }}$ percentile as a cutoff point, the odds ratio for impaired lipid profiles varied from 9.1 to 15.2 for males and females.

The associations between anthropometric measurements, fasting glucose and insulin levels, and lipid profiles, at each Tanner stage are presented in Tables 5 and 6 respectively, with $(\mathrm{P}<0.01$ and less $)$ for each group. Regression analyses were not required to establish significance.

\section{Study 2}

Table 7 shows the main anthropometric measurements of our study population at 7 different interval age groups from 9 to 38 years old. The BMI adjusted for age and sex was appropriate at each interval age group. CPR STR and 
Table 7: Anthropometric measurements by age group and sex from childhood to adulthood.

\begin{tabular}{|c|c|c|c|c|c|}
\hline Age group & Age (years) & BMI(\%) & CPR (ratio) & STR (index) & SUM \\
\hline \multicolumn{6}{|l|}{ Male } \\
\hline $9-12$ years $(\mathrm{N}=128)$ & $10.6 \pm 0.6$ & $86.4 \pm 1.1$ & $2.3 \pm 0.07$ & $1.5 \pm 0.05$ & $89 \pm 8$ \\
\hline $13-15$ years $(\mathrm{N}=128)$ & $14.3 \pm 0.4$ & $87.7 \pm 1.3$ & $2.4 \pm 0.05$ & $1.6 \pm 0.04$ & $110 \pm 6$ \\
\hline $16-19$ years $(N=128)$ & $18.1 \pm 0.5$ & $88.6 \pm 1.7$ & $2.5 \pm 0.07$ & $1.5 \pm 0.04$ & $123 \pm 7$ \\
\hline $20-23$ years $(\mathrm{N}=128)$ & $22.9 \pm 0.7$ & $86.3 \pm 2.2$ & $2.7 \pm 0.06$ & $1.8 \pm 0.05$ & $139 \pm 10$ \\
\hline $24-27$ years $(\mathrm{N}=128)$ & $26.3 \pm 0.6$ & $87.0 \pm 2.4$ & $2.8 \pm 0.06$ & $1.9 \pm 0.07$ & $155 \pm 9$ \\
\hline $28-31$ years $(N=\mid 28)$ & $28.5 \pm 1.4$ & $87.5 \pm 2.6$ & $3.2 \pm 0.07$ & $2.3 \pm 0.07$ & $173 \pm 11$ \\
\hline $32-38$ years $(\mathrm{N}=128)$ & $35.0 \pm 2.6$ & $87.0 \pm 2.6$ & $3.2 \pm 0.09 *$ & $2.4 \pm 0.08^{*}$ & $190 \pm 12^{*}$ \\
\hline \multicolumn{6}{|l|}{ Female } \\
\hline $9-12$ years $(\mathrm{N}=112)$ & $11.3 \pm 0.7$ & $85.6 \pm 1.4$ & $2.4 \pm 0.06$ & $1.3 \pm 0.05$ & $91 \pm 5$ \\
\hline $13-15$ years $(\mathrm{N}=112)$ & $13.6 \pm 0.4$ & $85.8 \pm 2.3$ & $2.5 \pm 0.07$ & $1.5 \pm 0.06$ & $112 \pm 7$ \\
\hline $16-19$ years $(\mathrm{N}=112)$ & $17.8 \pm 0.4$ & $87.9 \pm 1.8$ & $2.5 \pm 0.04$ & $1.6 \pm 0.04$ & $125 \pm 9$ \\
\hline $20-23$ years $(\mathrm{N}=112)$ & $21.2 \pm 0.6$ & $87.5 \pm 2.2$ & $2.7 \pm 0.06$ & $1.9 \pm 0.07$ & $144 \pm 9$ \\
\hline $24-27$ years $(\mathrm{N}=112)$ & $25.3 \pm 0.4$ & $87.9 \pm 2.1$ & $2.8 \pm 0.07$ & $1.8 \pm 0.06$ & $160 \pm 11$ \\
\hline $28-31$ years $(N=\mid 12)$ & $29.3 \pm 0.4$ & $87.2 \pm 1.7$ & $2.9 \pm 0.08$ & $2.1 \pm 0.06$ & $174 \pm 10$ \\
\hline $32-38$ years $(\mathrm{N}=112)$ & $35.1 \pm 0.5$ & $87.5 \pm 2.1$ & $3.1 \pm 0.07 *$ & $2.4 \pm 0.07^{*}$ & $192 \pm 13^{*}$ \\
\hline
\end{tabular}

CPR: subscapular skinfold + suprailliac skinfold) / (triceps skinfold+ thigh skinfold), STR: ratio of subscapular to triceps skinfold, SUM:triceps, subscapular, suprailliac and thigh skinfolds in the total sample. ${ }^{*}: \mathrm{P}<0.01$ significative difference between adulthood obesity and adolescent obesity.

Table 8: Incidence of impaired glucose and lipid profile by age group and sex from childhood to adulthood.

\begin{tabular}{lcccc}
\hline & $N$ & $\begin{array}{c}\text { Impaired glucose profile } \\
\text { Incidence (\%) }\end{array}$ & $\begin{array}{c}\text { Impaired lipid profile } \\
\text { No Cases }\end{array}$ \\
& & & & \\
Incidence (\%)
\end{tabular}

$*: \mathrm{P}<0.01$ significative difference between age groups.

SUM were significantly increased $(\mathrm{P}<0.01)$ with age corresponding with a higher fat mass with growth. For all the anthropometric measurements there were no significant gender differences.

Table 8 presents the incidence of impaired glucose and lipid profile between age groups. The incidences of im- paired glucose and lipid profiles were already high at the first age group with incidences of approximately $30 \%$ for both. The incidence increases progressively with age.

Fasting plasma glucose level (results not shown), HbA1c and fasting plasma insulin levels were significantly increased $(\mathrm{P}<0.01)$ through puberty and growth. There 
Table 9: Sensitivity, specificity, and odds ratios of the selected cutoff point for BMI values at the $85^{\text {th }}$ percentile at $13-15$ y old for identifying overweight at age $35 y$

\begin{tabular}{|c|c|c|c|c|c|}
\hline \multirow[t]{2}{*}{$\mathrm{BMl}$ at age $35 \mathrm{y}$} & \multicolumn{2}{|c|}{ BMI percentile at $13-15 y$} & \multirow[t]{2}{*}{ Sensitivity } & \multirow[t]{2}{*}{ Specificity } & \multirow[t]{2}{*}{ Odds ratio } \\
\hline &.$>85^{\text {th }}$ & $<85$ th & & & \\
\hline \multicolumn{6}{|l|}{ Males } \\
\hline$>25(n=110)$ & 88 & 24 & & $80.0 \%$ & \\
\hline$<25(\mathrm{n}=18)$ & 4 & 14 & $77.7 \%$ & & \\
\hline Total $(n=128)$ & 92 & 38 & & & 12.8 \\
\hline \multicolumn{6}{|l|}{ Females } \\
\hline$>25(n=100)$ & 80 & 20 & & $80.0 \%$ & \\
\hline$<25(\mathrm{n}=12)$ & 2 & 10 & $83.3 \%$ & & \\
\hline Total $(n=1 \mid 2)$ & 82 & 30 & & & 20.0 \\
\hline
\end{tabular}

Specificity $=88$ of I 10 subjects, Sensitivity: $\mid 4$ of 18 subjects. An odds ratio of $I 2.8$ means that the risk of $I 3-I 5$ years old adolescents with a BMI $\geq$ $85^{\text {th }}$ percentile of becoming an overweight or obese adults at $35 \mathrm{y}$ old is 12.8 times higher than in those with a BMI < than $85^{\text {th }}$ percentile

Table 10: Sensitivity, specificity, and odds ratios of the selected cutoff point for impaired fasting glucose (IFG) values at the $85^{\text {th }}$ percentile at 13-15 y old for identifying IFG at age $35 y$

\begin{tabular}{|c|c|c|c|c|c|}
\hline \multirow[t]{2}{*}{ BMI at age $35 y$} & \multicolumn{2}{|c|}{ BMI percentile at $13-15$ y } & \multirow[t]{2}{*}{ Sensitivity } & \multirow[t]{2}{*}{ Specificity } & \multirow[t]{2}{*}{ Odds ratio } \\
\hline &.$>85^{\text {th }}$ & $<85$ th & & & \\
\hline \multicolumn{6}{|l|}{ Males } \\
\hline$>25(n=110)$ & 84 & 26 & & $76.4 \%$ & \\
\hline$<25(\mathrm{n}=18)$ & 4 & 14 & $77.8 \%$ & & \\
\hline Total $(n=128)$ & 88 & 40 & & & 11.3 \\
\hline \multicolumn{6}{|l|}{ Females } \\
\hline$>25(n=98)$ & 76 & 22 & & $77.6 \%$ & \\
\hline$<25(\mathrm{n}=14)$ & 4 & 10 & $71.4 \%$ & & \\
\hline Total $(n=|| 2)$ & 80 & 32 & & & 8.6 \\
\hline
\end{tabular}

were no significant differences between sexes. TRG, TC, LDL and T:HDLC were also significantly increased $(\mathrm{P}<$ $0.01)$ with growth. The reverse was observed for HDL.

BMI values at the $85^{\text {th }}$ percentile for $13-15$ year old group were chosen as cutoff points for identifying overweight at age $35 \mathrm{y}$. The sensitivities were $77.7 \%$ and $83.3 \%$, and the specificities $80.0 \%$ and $80.0 \%$, for males and females respectively. With use of the cutoff point of the $85^{\text {th }}$ percentile at this age group, the odds ratios for overweight at age 35 y were 12.8 for males and 20.0 for females (Table 9).

Table 10 presents the sensitivity, specificity and odds ratios for the selected cutoff point for predicting impaired fasting glucose (IFG) values at the $85^{\text {th }}$ percentile at $13-15$ year old group, at age 35 . The sensitivities were $77.8 \%$ and $71.4 \%$, and the specificities $76.4 \%$ and $77.6 \%$ for males and females respectively. The odds ratios for abnormal IFG at age 35 y were 11.3 for males and 8.6 for females.

Table 11 presents the sensitivity, specificity and odds ratios for predicting impaired lipid profiles (ILP) at the $85^{\text {th }}$ percentile at 13-15 year old group, for age 35. The sensitivities were $80.0 \%$ and $75 \%$, and the specificities $77.7 \%$ and $79.2 \%$, for males and females respectively. With use of the cutoff point of the $85^{\text {th }}$ percentile at $13-15$ year old group, the odds ratios of ILP at age $35 \mathrm{y}$ were 14.0 for males and 11.4 for females.

\section{Discussion}

This study presents for the first time that: 1) obese and overweight adolescents at Tanner stages III and higher are at an increased risk of having impaired glucose and lipid profiles at maturity than normal subjects. Odds ratios of 9.0 and higher were measured in both genders. 2) all the 
Table I I: Sensitivity, specificity, and odds ratios of the selected cutoff point for Impaired lipid profile (ILP) values at the $85^{\text {th }}$ percentile at I3-I5 y for identifying (ILP) at age 35 y

\begin{tabular}{|c|c|c|c|c|c|}
\hline \multirow[t]{2}{*}{ BMI at age $35 y$} & \multicolumn{2}{|c|}{ BMI percentile at $13-15$ y } & \multirow[t]{2}{*}{ Sensitivity } & \multirow[t]{2}{*}{ Specificity } & \multirow[t]{2}{*}{ Odds ratio } \\
\hline &.$>85^{\text {th }}$ & $<85$ th & & & \\
\hline \multicolumn{6}{|l|}{ Males } \\
\hline$>25(n=108)$ & 84 & 24 & & $77.7 \%$ & \\
\hline$<25(\mathrm{n}=20)$ & 4 & 16 & $80.0 \%$ & & \\
\hline Total $(n=128)$ & 88 & 40 & & & 14.0 \\
\hline \multicolumn{6}{|l|}{ Females } \\
\hline$>25(n=96)$ & 76 & 20 & & $79.2 \%$ & \\
\hline$<25(n=16)$ & 4 & 12 & $75.0 \%$ & & \\
\hline Total $(n=|| 2)$ & 80 & 32 & & & 11.4 \\
\hline
\end{tabular}

anthropometric parameters tested were strongly $(\mathrm{P}<$ 0.01 ) associated with glucose and lipid profiles; 3 ), with a retrospective-prospective longitudinal study of the same subjects, the odds ratios of adolescents aged between 13 and 15 years old with a $\mathrm{BMI} \geq 85^{\text {th }}$ percentile to becoming overweight or obese at $35 \mathrm{y}$ old were 12.8 and 20.0 times higher than in those with a BMI $<$ than $85^{\text {th }}$ percentile for both male and female respectively, 4) with use of the same cutoff, the odds ratios of the same adolescents with $\mathrm{BMI} \geq 85^{\text {th }}$ percentile for impaired fasting glucose at $35 \mathrm{y}$ old were 11.3 times higher in males and 8.6 times higher in females and 5) the odds ratio of the same adolescents of having impaired lipid profiles, expressed by lipid profile values $\geq 85^{\text {th }}$ percentile at 35 y old is 14.0 in males and 11.4 in females. These observations suggest that between 13 to 15 years old is an appropriate age to initiate interventions in order to prevent adult obesity and its associated risk factors.

\section{Study I}

The rationale underlying this part of the study is that the stage of sexual maturation is an important variable in applying anthropometric measurements as predictors of risk for cardiovascular diseases. On average, BMI seems to increase with stage of genital maturation in boys relative to fatness, and then, in contrast, decreases in the later stages of maturation reflecting the rapid growth of fat free mass with puberty. BMI in girls also increases with stage of sexual maturation, but relative fatness is variable, especially in girls who just attaining menarche (stage III). To obviate this bias, we preselected our subjects according to their BMI. For instance a BMI $\geq 85^{\text {th }}$ percentile (for age and sex) was classified as being overweight, and those with a BMI $\geq 95^{\text {th }}$ percentile as obese [29-32]. Recent workshops concluded that the BMI is an index of choice for evaluating obesity in adolescents, because it has been validated by studies of total body fat [32]. The criteria used to identify overweight and obesity in children and adolescents agree with those used for grade 1 and grade 2 overweight (BMI of $25+$ and $30+$, respectively) in adults [33]. Using a representative sample from the general North American Caucasian population, we demonstrate that the BMI is also a good indicator for obesity in adolescents, however the readily-measured WC:AC, CPR, and STR, indices of central obesity, and SUM, a single measure of subcutaneous adiposity, are stronger predictor of both fasting glucose and insulin levels and lipid profiles, than BMI. We also demonstrated that each anthropometric variable taken separately can significantly predict fasting glucose and insulin levels and lipid profile in adolescents of both sexes with a probability of $\mathrm{P}<0.01$. Our results are in accordance with others of children aged 5 and 16, in whom, indicators of fatness such as weight-for-height, BMI and skinfold thicknesses have been associated with higher total and LDL cholesterol, lower HDL cholesterol, and higher triglyceride concentrations [40-43].

Our overweight and obese adolescents had higher fasting glucose, and insulin levels for BMI than subjects with BMI in the healthy range. Furtheremore, the prevalence of obesity was comparable between boys and girls. In both sexes the prevalence of diabetes and impaired fasting glucose increased relative to chronological age in both overweight $(P<0.01)$ and obese subjects $(P<0.001)$. Previous study in Aboriginal children recognized to be at high risk for type II diabetes has shown that obesity is associated with high fasting glucose and fasting insulin levels. They also demonstrated that children with BMI exceeding the $85^{\text {th }}$ percentile are at increased risk of diabetes or impaired fasting glucose, odds ratio of 5.1 with $95 \%$ coefficient interval 1.5, 17.0 [39]. With use of the cutoff point of the $85^{\text {th }}$ percentile we demonstrated that adolescents of Tanner stage III and higher, of both sexes, are at increased 
risk of having impaired fasting glucose, with odds ratios of 11.7 and higher.

Our overweight and obese adolescents had higher TC, LDL, TRG and lower HDL values which correlated with BMI, and other measures of fatness. In both sexes the prevalence of impaired lipid profile increased relative to chronological age in both overweight $(P<0.01)$ and obese subjects $(P<0.001)$ l. Adolescents of both sexes, with $B M I \geq 85^{\text {th }}$ are at increased risk of impaired fasting lipid profiles, with odds ratios of 9.1 and higher.

\section{Study 2}

The goal of the second study was to determine the childhood age of abnormal glucose and lipid profiles from overweight adults. By using a retrospective-prospective longitudinal study design we were able to track BMI, glucose and lipid profiles from late childhood and adolescent ages to adulthood in a white Caucasian populations. Then we were able to correlate their subsequent risk of obesity and its associated impaired glucose and lipid profiles There is general agreement on the use of BMI with selected cutoff points as guidelines for desirable weight [4448]. This study provided a basis for prediction of overweight and obesity in adults from their 13-15 year old group, suggesting that this simple measurement could be applied to the prediction of obesity in public health programs. The results presented here were comparable to those observed in a previous study showing that with use of the cutoff point of the $60^{\text {th }}$ percentile at age $18 \mathrm{y}$, the odds ratios of overweight at age $35 \mathrm{y}$ were of 15 for males and 27 for females, with corresponding SEs of 1.9 and 3.5 respectively. Previous data on $8-18$ y olds in Project Heart-Beat demonstrated that the odds ratio of overweight in adulthood for those with childhood BMI values at the $95^{\text {th }}$ percentile were $2-6$ and 1.5 to 5 times as great as for those with a BMI values at the $75^{\text {th }}$ percentile for males and females respectively [49].

The incidence of impaired glucose profile was comparable between boys and girls. In both sexes the incidence of diabetes and impaired fasting glucose increased significantly $(P<0.001)$ relative to chronological age in comparison to adults. The sensitivity of the selected cutoff point for BMI values at the $85^{\text {th }}$ percentile at $13-15$ years old for identifying impaired glucose profile at age $35 \mathrm{y}$ was $76.4 \%$ and $77.6 \%$ for both male and female, respectively. Therefore, at least $75 \%$ of male and female adolescents aged between 13 and 15 years old who were having a BMI $\geq 85^{\text {th }}$ were correctly predicted to have impaired glucose profile at $35 \mathrm{y}$. On the other hand, $77.8 \%$ of male and $71.4 \%$ of female adolescents of this age group who were having a $\mathrm{BMI} \leq 85^{\text {th }}$ were correctly predicted to have normal glucose profile at $35 \mathrm{y}$. As stated in the introduction obesity in childhood is associated with obesity in adulthood [22-
25], and is a predictor of all cause of obesity-associated mortality during adulthood, particularly mortality from cardiovascular diseases, which is independent of adult weight $[24,25]$. The results of the present study agreed with a previous study [50] indicating that the metabolic alterations caused by excess body fat are expressed early in the natural history of obesity. Such alterations seem clinically important even in children, as evidenced by an increase in glucose profile abnormalities in obese adolescents. These observations underscore the need for research efforts directed at the development of effective interventions for obese adolescents.

The incidence of impaired lipid profile was comparable between boys and girls. In both sexes the incidence of impaired lipid profile increased significantly $(P<0.001)$ relative to chronological age in comparison to adults. The sensitivity of the selected cutoff point for BMI values at the $85^{\text {th }}$ percentile at $13-15$ years old for identifying impaired lipid profile at age $35 \mathrm{y}$ was $77.7 \%$ and $79.2 \%$ for both male and female, respectively. The specificity was $80.0 \%$ and $75.0 \%$, for both male and female, respectively. If we consider that most of the subjects having a $\mathrm{BMI} \geq 85^{\text {th }}$ were also presenting more than 2 risk factors for cardiovascular disease, this means that they are at increased risk for developing cardiovascular diseases. Few studies have examined the long-term effects of adolescent obesity on adult disease. Nonetheless, obesity present in childhood or adolescence seems to increase the likelihood of adult morbidity and mortality [51]. In the present study we demonstrated that in both men and women obese during adolescence, risk of cardiovascular diseases and diabetes were increased. These effects seems related both to the persistence of obesity and to the effects of childhood or adolescent obesity on the quantity and location of body fat distribution. The risk factors for adult disease that are associated with obesity in children and adolescents persist into adulthood or increase in prevalence if weight gain occurs. Although both total body fat and regional fat deposition could account for the association of childhood or adolescent obesity with adult disease, no studies to date have examined cardiovascular risk factors and related them to visceral fat.

\section{Conclusion}

The strengths of the study include the use of large samples of both genders, a wide age range, subjects representative of the population being studied, precise measurements of body composition and the use of well-accepted BMI classifications of overweight and obesity. By using a retrospective-prospective design in the second part of the study we were able to obtain the longitudinal data required to answer the questions addressed. In conclusion our study confirms the hypothesis that overweight and obese adolescents have higher fasting plasma glucose and insulin 
levels, and an abnormal lipid profile relative to their lean peers. This study highlights the critical importance of early identification and intervention of adolescent obesity to avert the long-term consequences of it and to protect adolescent against the risk of cardiovascular diseases. There is an urgent need to follow cohorts at-risks children and adolescents to investigate cofactors acting in concert with obesity that are responsible for the early onset of risk factors for cardiovascular diseases, a phenomenon increasingly being observed in many populations.

\section{Competing interests}

None declared.

\section{Acknowledgements}

The author would like to acknowledge Sylvie Rondeau for its technical support. We would like to acknowledge Dr Richard N Pierson director of the Body Composition Research Unit St-Luke's-Roosevelt Hospital, Columbia University, New-York, for its editing of this manuscript.

\section{References}

I. National Institutes of Health Consensus Development Panel on the Health Implications of Obesity. Health Implications of Obesity November 1997

2. Lew E: Mortality and Weight: Insured Lives and the American Cancer Society Studies. An Intern Med 1985, 103:1024-1029

3. Hubert H, Feinlieb M, McNamara P, Castelli W: Obesity as an Independent Risk Factor for Cardiovascular Disease: A 26-year Follow-up of Participants in the Framingham Heart Study. Circulation 1983, 67:968-977

4. Donahue R, Bloom E, Abbott R, Reed D, Yano K: Central Obesity and Coronary Heart Disease in Men. Lancet 1987, 8I-824

5. Atkintewe TA, Adetuyibi A: Obesity and Hypertension in Diabetic Nigerians. Tropical Geographic Medicine 1986, 38(2): I 46- 149

6. Beegon R, Niaz MA, Singh RB: Diet, central obesity and prevalence of hypertension in the urban population of south India. Center of Nutrition Research, Moradabad, India. Internal Journal of Cardiology 1995, 5 I (2):83-191

7. Foster C, Rotimi C, Fraser H, Sundarum C, Liao Y, Gibson E, Holder $Y$, Hoyos M, Mellanson-King R: Hypertension, diabetes and obesity in Barbados: findings from a recent population-based survey. Ethnic Diseases 1993, 3(4):404-412

8. Cassano PA, Segal MR, Vokonas PS, Weiss ST: Body fat distribution, blood pressure, and hypertension. A prospective study of men in the normative aging study. Division of Nutritional Sciences, Cornell University, Ithaca, New York. Ann Epidemiology 1990, I:33-48

9. Kannel WB, McGee D, Gordon T: A general cardiovascular risk profile: The Framingham Study. Am J Cardiol 1976, 38:46-5 I

10. Carey $\mathrm{V}$, Walters $\mathrm{E}$, Colditz $\mathrm{G}$, et al: Body fat distribution and risk of non-insilin-dependent diabetes mellitus in women. The Nurses' Health Study. Am J Epidemiol 1997, 145:6I4-619

II. Bjorntorp P: Abdominal fat distribution and metabolic syndrome. J Cardiovasc Pharmacol 1992, 20(Suppl. 8):S26-S28

12. Kissenbah AH, Peiris AN: Biology of regional fat distribution: relationship to non-insulin-dependent diabetes mellitus. Diabetes Metab Rev 1989, 5:83-109

13. Biontorp P: Regional obesity in NIDDM. Adv Exp Med Biol 1993, 334:279-285

14. Després J: Abdominal obesity as important component of insulin-resistance syndrome. Nutrition 1993, 23:452-459

15. Clark WR, Lauer RM: Does childhood obesity track into adulthood?. Crit Rev Food Sci Nutr 1993, 33:423-430

16. Johnston FE: Health implication of childhood obesity. Ann Intern Med 1985, 103:1068-1072

17. Dietz WH: Critical Periods in childhood for the development of obesity. Am J Clin Nutr 1994, 59:955-959

18. Gortmarker SL, Dietz WH, Sobol AM, Wehler CA: Increasing pediatric obesity in the United States. Am J Dis Child 1987, 141:535-540
19. Troiano RP, Flegal KM, Kuczmarski RJ: Overweight prevalence and trends for children and adolescents. Arch Pediatr Adolesc Med 1995, 149:|085-109|

20. Freedman DS, Srinivasan SR, Valdez RA, et al: Secular increases in relative weight and adiposity among children over two decades: the Bogalusa Heart Study. Pediatrics 1997, 99:420-426

21. Figueroa-Colon R, Lee J, Aldridge R, Alexander L: Obesity is prevalent and progressive in Birmingham scholl children. Int J Obes Relat Metab Disor 1994, 18:26 abstract

22. Freedman DS, Shear CL, Burke GL, Srinivasan SR, et al: Persistence of juvenile-onset obesity over eight yaers:the Bogalus Heart Study. Am J Public Health 1987, 77:588-592

23. Lauer RM, Clarke WR: Childhood risk factors for high adult blood pressure: the Muscatine Study. Pediatrics 1984, 84:63364l

24. Javier-Nieto F, Szklo M, Comstock GW: Childhood weight and growth rate as predictors of adult mortality. Am J Epidemiol 1992, 136:201-203

25. Must A, Jacques PF, Dallal GE, et al: Long-term morbidity and mortality of overweight adolescents: a follow-up of the Harvard Group Study of 1922 to 1935 N Engl J Med 1992, 327: I 350 1355

26. Tracy RE, Newman WP, Wattigney WA, Berenson GS: Risk factors and atherosclerosis in young autopsy findings of the Bogalusa Heart Study. Am J Med Sci 1995, 3 I 0:S37-4I

27. Berenson GS, Wattigney WA, Bao W, Srinivasan SR, et al: Rationale to study the early natural history of heart disease: the Bogalusa Heart Study. Am J Med Sci 1995, 31 0:S22-S28

28. Pinhas-Hamiel O, Dolan LM, Daniels SR, et al: Increased incidence of non-insulin-dependant diabetes mellitus among adolescents. J Pediatr 1996, I 28:608-6I5

29. Must A, Dall GE, Dietz WH: Reference data for obesity: $85^{\text {th }}$ and $9^{\text {th }}$ percentiles of body mass index ( $\left.\mathrm{wt} / \mathrm{ht} 2\right)$ and triceps skinfold thickness. Am J Clin Nutr I99I, 53:839-846Erratum to Am J Clin Nutr. 1991:54: 773.

30. Himes JH, Dietz WH: Guidelines for overweight in adolescents preventive services: recommendations from an expert committee. Am J Clin Nutr 1994, 59:307-316

31. Barlow SE, Dietz WH: Obesity evaluation and treatment expert comittee recommendations. Pediatrics 1998, 102:e29

32. Dietz WH, Bellizzi MC: Introduction: the use of body mass index to assess obesity in children. Am J Clin Nutr 1999, 70(suppl): $123 \mathrm{~S}-125 \mathrm{~S}$

33. World Health Organization: Physical status: the use and interpretation of anthropometry. Report of a WHO Expert Committee. Geneva: WHO; (Tech Rep Ser 854). 1995

34. Brambilla P, Manzoni P, Sironi S, et al: Peripheral and abdominal obesity in childhood obesity. Int J Obes Relat Metab Disor 1994, 18:795-800

35. Tanner JM: Growth at adolescence. Oxford, United Kingdom: Blackwell 1962

36. Young CM, Bogan AD, Roe DA, Lutwak L: Body composition of pre-adolescent and adolescent girls. IV. Total body water and creatinine excretion. J Am Diet Assoc 1968, 53:579-587

37. Expert Committee on the diagnosis and classification of Diabetes Mellitus: Report of the Expert Committee on the Diagnosis and classification of diabetes Mellitus. Diabetes Care 1997, 20: I 1831258

38. Nationale Heart, Lung and Blood Institute: National Cholesterol Education Program 1999 [http://www.NHLBI.NIH.gov]

39. Young TK, Dean HJ, Flett B, Wood-Steiman P: Childhood obesity in a population at high risk for type 2 diabetes. J Pediatr 2000, 136:365-369

40. Rona RJ, Qureshi S, Chinn S: Factors related to total cholesterol and blood pressure in British 9 years old. J Epidemiol Commun Health 1996, 50:512-518

4I. Forrester TE, Wilks RJ, Bennett Fl, et al: Fetal growth and cardiovascular risk factors in Jamaican schoolchildren. $\mathrm{Br}$ Med J 1996, 312:156-160

42. DeStefano F, Berg RL, Griese GG: Determinants of serum lipid and lipoprotein concentrations in children. Epidemiology 1995 , 6:446-449

43. Craig SB, Bandini LG, Lichtenstein AH, et al: The impact of physical activity on lipids, lipoproteins, and blood pressure in preadolescents girls. Pediatrics 1996, 98:389-395 
44. Guo SS, Chumlea WC: Tracking of body mass index in children in relation to overweight in adulthood. Am J Clin Nutr 1999, 70: |45S-148S

45. Van Italie T: Health implications of overweight and obesity in the United States. Ann Intern Med 1985, I03:983-988

46. Roche AF: Growth, maturation and body composition. The Fels Longitudinal study 1929-1991. Cambridge. United Kingdom: cambridge University Press 1992

47. Jones MC, Bayley N, MacFarland JW, Honzik MP: The course of human development. Waltham, MA:Xerox College Publishing 197I

48. Stuart HC, Reed RB: Longitudinal studies of child health and development, description of project. Ediatrics 1959, 24:875-885

49. Labarthe DR, Nichman MZ, Harrist RB, et al: Development of cardiovascular risk factors from age 8 to 18 in project HeartBeat!. Circulation 1997, 95:2636-2642

50. Caprio S, Tamborlane WV: Metabolic impact of obesity in childhood. Endo and Metab Clinics of North America 1999, 28:73 I-747

51. Dietz WH: Chilhood weight affects adult morbidity and mortality. J of Nutrition 1998, I 28:4 I IS-4I4S

\section{Pre-publication history}

The pre-publication history for this paper can be accessed here:

http://www.biomedcentral.com/1471-2296/3/18/prepub
Publish with BioMed Central and every scientist can read your work free of charge

"BioMedcentral will be the most significant development for disseminating the results of biomedical research in our lifetime."

$$
\text { Paul Nurse, Director-General, Imperial Cancer Research Fund }
$$

Publish with BMC and your research papers will be:

- available free of charge to the entire biomedical community

- peer reviewed and published immediately upon acceptance

- cited in PubMed and archived on PubMed Central

- yours - you keep the copyright

Submit your manuscript here:

http://www.biomedcentral.com/manuscript/
BioMedcentral.com editorial@biomedcentral.com 